\title{
Analysis of membrane protein genes in a Brazilian isolate of Anaplasma marginale
}

\author{
Daniel SG Junior ${ }^{1}$, Flábio R Araújo ${ }^{2}{ }^{+}$, Nalvo F Almeida Junior ${ }^{3}$, Said S Adi ${ }^{3}$, Luciana M Cheung ${ }^{3}$, \\ Stenio P Fragoso ${ }^{4}$, Carlos AN Ramos², Renato Henrique M de Oliveira ${ }^{2}$, Caroline S Santos', \\ Gisele Bacanelli², Cleber O Soares ${ }^{2}$, Grácia MS Rosinha ${ }^{2}$, Adivaldo H Fonseca ${ }^{1}$
}

\author{
${ }^{1}$ Pós-Graduação em Ciências Veterinárias, Universidade Federal Rural do Rio de Janeiro, Seropédica, RJ, Brasil \\ ${ }^{2}$ Embrapa Gado de Corte, BR 262 Km 4, 79002-970 Campo Grande, MS, Brasil ${ }^{3}$ Universidade Federal de Mato Grosso do Sul, \\ Campo Grande, MS, Brasil ${ }^{4}$ Instituto de Biologia Molecular do Paraná, Curitiba, PR, Brasil
}

The sequencing of the complete genome of Anaplasma marginale has enabled the identification of several genes that encode membrane proteins, thereby increasing the chances of identifying candidate immunogens. Little is known regarding the genetic variability of genes that encode membrane proteins in $\mathrm{A}$. marginale isolates. The aim of the present study was to determine the degree of conservation of the predicted amino acid sequences of OMP1, OMP4, OMP5, OMP7, OMP8, OMP10, OMP14, OMP15, SODb, OPAG1, OPAG3, VirB3, VirB9-1, PepA, EF-Tu and AM854 proteins in a Brazilian isolate of A. marginale compared to other isolates. Hence, primers were used to amplify these genes: omp1, omp4, omp5, omp7, omp8, omp10, omp14, omp15, sodb, opag1, opag3, virb3, VirB9-1, pepA, ef-tu and am854. After polimerase chain reaction amplification, the products were cloned and sequenced using the Sanger method and the predicted amino acid sequence were multi-aligned using the CLUSTALW and MEGA 4 programs, comparing the predicted sequences between the Brazilian, Saint Maries, Florida and A. marginale centrale isolates. With the exception of outer membrane protein (OMP) 7, all proteins exhibited 92-100\% homology to the other A. marginale isolates. However, only OMP1, OMP5, EF-Tu, VirB3, SODb and VirB9-1 were selected as potential immunogens capable of promoting cross-protection between isolates due to the high degree of homology (over 72\%) also found with A. (centrale) marginale.

Key words: membrane proteins - OMPs - Anaplasma marginale - Brazil

The outer membranes of tick-transmitted intracellular bacterial pathogens determine the functions necessary for survival, replication and transmission. Thus, proteins expressed on the surfaces of these pathogens are potential candidates for vaccine development, targeting the induction of protective immune responses in the vertebrate hosts and/or prevention of the colonization of the tick vector. The identification of surface proteomes is critical to the development of vaccines and this process has been accelerated by genome sequencing (Noh et al. 2008). A number of complete genome sequences of the family Anaplasmataceae have recently been reported, including Anaplasma marginale (Brayton et al. 2005), Anaplasma marginale ss. centrale (Herndon et al. 2010), Anaplasma phagocytophilum, Ehrlichia chaffeensis, Neorickettsia sennetsu (Hotopp et al. 2006), Ehrlichia canis (Mavromatis et al. 2006) and Ehrlichia ruminantium (Collins et al. 2005).

Genome sequencing and subsequent proteomic studies of $A$. marginale have enabled the identification of several membrane proteins and have expanded the range of vaccine candidates (Lopez et al. 2005, 2008, Brayton

Financial support: CNPq, FUNDECT, FINEP

+Corresponding author: flabio@enpgc.embrapa.br

Received 13 January 2010

Accepted 18 May 2010 et al. 2006, Noh et al. 2008). However, some membrane proteins of this rickettsia vary between and even within isolates, depending on the rickettsemia cycle (Palmer et al. 2000). In the case of the major surface protein (MSP)2, genetic variability is due to the rearrangement of more than 10 whole functional pseudogenes with a single gene expression site (Brayton et al. 2001, 2005). The number of distinct configurations is exponentially increased by the conversion of gene segments, in which mosaics from the expression site are generated by the recombination of oligonucleotide segments from multiple allele donors (Barbet et al. 2000, Brayton et al. 2002, Palmer et al. 2009). This process involves rickettsia evasion from the immune response and ensures the maintenance of infections with low cyclical rickettsemia in the immune host (Palmer et al. 2000). Genetic variability is one of the factors to be considered in the evaluation of candidates for the development of vaccines, as it can result in significant antigen polymorphism and impair cross-protection between isolates (Palmer et al. 2000).

The aim of the present study was to assess the conservation of membrane proteins from a Brazilian isolate of $A$. marginale and compare the findings with other known isolates.

\section{MATERIALS AND METHODS}

A. marginale isolate - The Pernambuco-Zona da Mata isolate of $A$. marginale (AMBR) was maintained in liquid nitrogen, in the stabilized form of infected blood containing 10\% glycerol at Embrapa Gado de Corte (Brazilian 
TABLE I

Primer sequences used to amplify Brazilian Anaplasma marginale isolate

\begin{tabular}{|c|c|c|c|c|}
\hline Gene & Primer & Sequence (5'-3') & Amplicon size (bp) & Region \\
\hline \multirow{2}{*}{ Ompl } & $\mathrm{F}$ & AAGGTCTACGGCTTGGTTTACGCTGCGTTGTCTTT & \multirow{2}{*}{977} & \multirow{2}{*}{$1027576-1025552$} \\
\hline & $\mathrm{R}$ & AGTCTGATACCGCACTCAAACCCAAAATAGTCCAG & & \\
\hline \multirow{2}{*}{ Omp4 } & $\mathrm{F}$ & CAGCATATCATTGAATACAGGAGGAAGTCGCTTAT & \multirow{2}{*}{1,128} & \multirow{2}{*}{$1040447-1041574$} \\
\hline & $\mathrm{R}$ & GTGGCTAGCCGCTTTGGAGATGTTACCAG & & \\
\hline \multirow{2}{*}{ Omp5 } & $\mathrm{F}$ & CTGGTGGTGGAGAGTTTGCCTATG & \multirow{2}{*}{1,112} & \multirow{2}{*}{$1041985-1043096$} \\
\hline & $\mathrm{R}$ & AACTCGAGCTTCAGCCCCAGATTG & & \\
\hline \multirow{2}{*}{ Omp7 } & $\mathrm{F}$ & тCTTTTCTGTTGGGTGCGGTTGTA & \multirow{2}{*}{1,121} & \multirow{2}{*}{$1088542-1089662$} \\
\hline & $\mathrm{R}$ & CGCGCCTTGACATCTTCCTC & & \\
\hline \multirow{2}{*}{ Omp8 } & $\mathrm{F}$ & TTTCTGTTGAGCGCGGTTGTAGTT & \multirow{2}{*}{1,127} & \multirow{2}{*}{$1089797-1090923$} \\
\hline & $\mathrm{R}$ & CGCGCTCTGATATTTTCCCTTTCA & & \\
\hline \multirow{2}{*}{ Omp10 } & $\mathrm{F}$ & TTGCTGCGTTGCGACGGTTTC & \multirow{2}{*}{1,202} & \multirow{2}{*}{$1092307-1093508$} \\
\hline & $\mathrm{R}$ & GCGAGATTCAACACCCCAAAAGAG & & \\
\hline \multirow{2}{*}{ Omp14 } & $\mathrm{F}$ & GCGTTTAGCCTCCTGTT & \multirow{2}{*}{1,207} & \multirow{2}{*}{$63058-64247$} \\
\hline & $\mathrm{R}$ & ATCCGAACCTGATTCCTA & & \\
\hline \multirow{2}{*}{ Omp15 } & $\mathrm{F}$ & GAATTCACGCATATACCTTGGCTCACCGTT & \multirow{2}{*}{422} & \multirow{2}{*}{$900095-900516$} \\
\hline & $\mathrm{R}$ & GAATTCCTATATTGCGTAGCCCGAAGGATGCTGAGA & & \\
\hline \multirow{2}{*}{ Am097 } & $\mathrm{F}$ & ATGAAAAAGGCTTTCATGGTTT & \multirow{2}{*}{813} & \multirow{2}{*}{$77775-78587$} \\
\hline & $\mathrm{R}$ & CTACCCACGTCCCCTTCTG & & \\
\hline \multirow{2}{*}{ Am197 } & $\mathrm{F}$ & ATGAAAAAGCTTGAGCTTGCTAG & \multirow{2}{*}{510} & $166838-167347$ \\
\hline & $\mathrm{R}$ & CTACTTGGGCTTTCTAGGAGCC & & 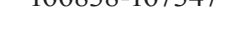 \\
\hline $\operatorname{Am} 254$ & $\mathrm{~F}$ & ATGACAGAAGGGAGAAAGCC & 1182 & $832189-833370$ \\
\hline 1 191207 & $\mathrm{R}$ & СТАСТССАAАATCTCAGTTATGATAC & 1,102 & 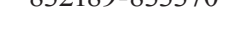 \\
\hline $4 m 854$ & $\mathrm{~F}$ & ATGCTGCATCGTTGGTTAGC & 711 & $780000-780710$ \\
\hline 11m0 & $\mathrm{R}$ & CTATTCAGGCGCGACCAC & & ש \\
\hline $4 m 056$ & $\mathrm{~F}$ & ATGTGCTATGGTACTCGCATC & 1605 & $876183-877787$ \\
\hline АПМУग & $\mathrm{R}$ & TCACTTTTCGTAATACTTCGACACA & 1,000 & (201000 \\
\hline Ongol & $\mathrm{F}$ & AGTTGCAGAGCATTTTCCTTG & 390 & $1030618-1031007$ \\
\hline Opagi & $\mathrm{R}$ & CTAAAAAACCAAAAAAACCGT & 390 & 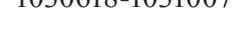 \\
\hline Onga 3 & $\mathrm{~F}$ & TGTGGGTTGCACACACTACC & 036 & $1028730-1029665$ \\
\hline Opaga & $\mathrm{R}$ & CTAAAAACCATCACCAAATGC & & \\
\hline Virh3 & $\mathrm{F}$ & TCGTCCGGTAGCGTAAAGAC & 294 & $752143-752436$ \\
\hline Vor & $\mathrm{R}$ & CTACATCACATCGTAAGAATT & 274 & 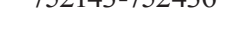 \\
\hline $\operatorname{SodB}$ & $\mathrm{F}$ & TCACACACCCGCGGTTTCAAGCCT & 664 & $752533-753196$ \\
\hline & $\mathrm{R}$ & TCCGCTGCGCAGTTGGTATACAT & & \\
\hline
\end{tabular}


Cattle Research Institute), Campo Grande, Mato Grosso do Sul, Brazil. Rickettsemia in the sample at the time of the preparation of the stabilized solution was $87 \%$.

DNA extraction was performed with the Easy-DNA ${ }^{\mathrm{TM}}$ kit (Invitrogen) according to the manufacturer's instructions. The concentration of extracted DNA and the $\mathrm{A}_{260} /$ $\mathrm{A}_{280}$ ratio were determined with a GeneQuant spectrophotometer (Amersham Pharmacia Biotech, USA).

Gene amplification by polimerase chain reaction (PCR) for sequencing - The membrane proteins prioritized in this work were those for which less information was available and for which amplification was successful. Primers were designed as described in Ramos et al. (2007) for the amplification of the ompl, omp4, omp5, omp7, omp8, omp10, omp14, omp15, sodb (am197), opag1, opag3, virb3, virb 9-1 (conjugal transfer protein/am097), pepA (am956), ef-tu (am254) and am854 genes (Table I) using the PCR. Amplification reaction mixtures were prepared in a volume of $25 \mu \mathrm{L}$ containing $10 \mathrm{mM}$ Tris- $\mathrm{HCl}(\mathrm{pH}$ 8.3), $50 \mathrm{mM} \mathrm{KCl}, 1.5 \mathrm{mM} \mathrm{MgCl}, 0.2 \mathrm{mM}$ of each deoxynucleoside triphosphate, $12 \mathrm{pmol}$ of each primer, $100 \mathrm{ng}$ of genomic DNA and 1.25 U of Taq DNA polymerase (Invitrogen). Amplifications were carried out in a thermocycler (MyCycler, Biorad) as follows: $94^{\circ} \mathrm{C}$ for $1 \mathrm{~min}$ (denaturation), 30 cycles at $94^{\circ} \mathrm{C}$ for $1 \mathrm{~min}$ (denaturation), $55^{\circ} \mathrm{C}$ for $30 \mathrm{~s}$ (annealing) and $72^{\circ} \mathrm{C}$ for $1 \mathrm{~min}$ (extension). The PCR products were analyzed by electrophoresis in $1 \%$ agarose gels stained with SybrGold (Invitrogen).
The amplicons were cloned in the pGEM-T Easy plasmid (Promega, USA) according to the manufacturer's instructions. The recombinant plasmids were then used to transform Escherichia coli (TOP-10) cells, which were seeded in Luria-Bertani agar (LB) containing $100 \mu \mathrm{g} / \mathrm{mL}$ ampicillin. The plates were incubated at $37^{\circ} \mathrm{C}$ for approximately $12 \mathrm{~h}$ and the colonies were analyzed by PCR with M13 primers to confirm the presence of the inserts. Colonies that were PCR-confirmed to contain the inserts (1 per gene) were grown in $\mathrm{LB}$ broth with ampicillin and at $37^{\circ} \mathrm{C}$ for $12 \mathrm{~h}$ with agitation. The cells were then recovered by centrifugation and plasmid DNA was extracted using the Wizard Plus Miniprep kit (Promega).

Sequencing and analysis - Sequencing reactions were performed using the BigDye Terminator (Applied Biosystems), following the manufacturer's instructions. Gene sequences were obtained with an automatic sequencer (model ABI 3130, Applied Biosystems). Four sequencing reactions were performed for each gene, two with the M13 forward primer and two with the M13 reverse primer.

The gene sequences were assembled and the consensus sequences were generated with the Sequencher program v.4.1.4 (Gene Codes). The search for homologues was performed using the BLASTn program (ncbi.nlm.nih.gov) with comparisons to the sequences obtained from the following A. marginale isolates: Saint Maries (AMSM) (Genbank CP000030), Florida (AMFL) (Genbank CP001079) and $A$. marginale centrale (AMCE) (Genbank CP001759).

TABLE II

Percentage of identity between the predicted amino acid (AA) sequences in the membrane proteins of the Pernambuco-Zona da Mata isolate of Anaplasma marginale (AMBR) compared to the American isolates Saint Maries (AMSM), Florida (AMFL) and $A$. (centrale) marginale (AMCE)

\begin{tabular}{|c|c|c|c|c|c|}
\hline AMBR protein & $\begin{array}{c}\mathrm{AAs} \\
\mathrm{n}\end{array}$ & $\begin{array}{c}\text { AMBR GenBank } \\
n\end{array}$ & $\begin{array}{c}\text { AMSM } \\
\%\end{array}$ & $\begin{array}{c}\text { AMFL } \\
\%\end{array}$ & $\begin{array}{c}\mathrm{AMCE} \\
\%\end{array}$ \\
\hline AM854 & 236 & GU991617 & 100 & 100 & - \\
\hline OMP1 & 329 & GU991619 & 99 & 99 & 72 \\
\hline OMP4 & 404 & GU991620 & 92 & 92 & 66 \\
\hline OMP5 & 380 & GU991621 & 97 & 94 & 75 \\
\hline OMP7 & 381 & GU991622 & 65 & 72 & 40 \\
\hline OMP8 & 399 & GU991623 & 97 & 92 & 66 \\
\hline OMP10 & 420 & GU991624 & 100 & 98 & 65 \\
\hline OMP14 & 404 & GU991625 & 95 & 94 & 70 \\
\hline OMP15 & 147 & GU991626 & 94 & $\S$ & \# \\
\hline OPAG1 & 130 & GU991627 & 100 & 100 & \# \\
\hline OPAG3 & 312 & GU991628 & 95 & 95 & 66 \\
\hline EF-Tu & 393 & GU991618 & 100 & 100 & 97 \\
\hline PepA & 518 & GU991629 & 97 & 97 & 65 \\
\hline VirB3 & 98 & GU991632 & 100 & 100 & 96 \\
\hline ViB9-1 & 270 & GU991631 & 97 & 100 & 97 \\
\hline SODb & 223 & GU991630 & 99 & 100 & 89 \\
\hline
\end{tabular}

$\S$ : the OMP15 predicted amino acid sequence of the AMFL (available on GenBank) is incomplete; \#: A. marginale centrale does not have the complete genes that codify the proteins AM854, OMP15 and OPAG1 in its genome. 
Predicted amino acid sequences for the genes of AMBR were obtained using the MEGA 4 program (Tamura et al. 2007) and multiple alignments between these sequences and those from the AMSM, AMFL and AMCE isolates was performed using the CLUSTALW program (ebi.ac.uk/Tools/clustalw2/index.html).

\section{RESULTS}

Most of the alignments of predicted amino acid sequences of membrane proteins from the Brazilian (Table II) and American A. marginale isolates were more than $92 \%$ homologous (Table II), thereby demonstrating conservation.

A. marginale membrane protein genes are grouped into two superfamilies, MSP1 and MSP2 (Brayton et al. 2005). Most members of the MSP1 superfamily in the American sensu stricto isolates (AMSM and AMFL), such as MSP1a, MSP1b 1-2 and MLP 2-4, have low degrees of conservation, with only $13-48 \%$ homology between amino acid sequences (Herndon et al. 2010). The MSP2 superfamily has a number of conserved genes, some of which were studied in the present investigation.

Operon-associated genes (OPAG) 1 and 3 are components of the MSP2 superfamily and their function remains unknown (Löhr et al. 2002). The observation that bacterial structural genes are often organized into groups that encode proteins with related functions (Lewin 2000, Löhr et al. 2002) suggests that OPAG proteins take part in interactions in the membrane of $A$. marginale. It is unknown whether the $O P A G 1$ gene is expressed in small amounts or not expressed at all. OPAG3 is expressed only within erythrocytes during acute rickettsemia. The differential expression of outer membrane proteins (OMP) within the same operon is a new finding in ticktransmitted bacteria and expression regulation should be broadly applicable in order to understand how the pathogen adapts to transitions in the host (Löhr et al. 2002).

The American isolates exhibit identical predicted OPAG1 and OPAG3 amino acid, with $100 \%$ and $95 \%$ homology with AMBR sequences, respectively. AMCE does not have the OPAG1 gene and its predicted amino acid sequence for $O P A G 3$ demonstrated only $66 \%$ homology with AMBR isolate sequence. Therefore, although the degree of conservation in the OPAGl gene is greater than that found in $O P A G 3$ for the AMSM and AMFL isolates, $O P A G 3$ is probably a better candidate vaccine component. However, while AMCE lacks the OPAGI gene, the immunity achieved by vaccination with this isolate is sufficient to prevent the development of clinical disease in cattle (Pipano 1995). How this protection is achieved with $O P A G 3$ remains unknown.

Fifteen OMP with sequences similar to those of MSP2 and/or MSP4 have been identified in the MSP2 superfamily. These genes can be separate or grouped in structures similar to an operon (Brayton et al. 2006). Within this group, OMP2, OMP3 and OMP6 are probably pseudogenes, as their transcripts have not been detected in erythrocyte stages of different $A$. marginale isolates (Noh et al. 2006, Ramos et al. 2007).

The functions of OMPs 4, 7, 10 and 14 remain undefined in A. marginale. These proteins are designated as members of the MSP2 superfamily due to sequence identity with surface antigens of the PFAM01617 family (Brayton et al. 2005). However, these OMPs are the targets of antibodies induced by the immunization of cattle with purified outer membranes (Lopez et al. 2005) and specifically by $\operatorname{IgG} 2$, which is associated with protective immunity (Brown et al. 1998).

The vaccine isolate AMCE has OMP1, OMP4, OMP5, OMP7, OMP9, OMP10, OMP11, OMP12, OMP13 and OMP14 genes in its genome (Genbank CP001759). According to Herndon et al. (2010), the family of OMPs 1-15 present in the sensu stricto American isolates of $A$. marginale is reduced in AMCE. The latter has no distinct omp 7 , omp 8 or omp 9 genes; they are assembled into a single coding region, constituting an operon and OMP 2, 3, 6 and 15 homologues are missing. In the present study, not all the genes in AMCE were studied; however, the predicted amino acid sequences of OMPs $1,4,5,7,8$, 10 and 14 exhibited $72 \%, 66 \%, 75 \%, 38 \% 65 \%, 65 \%$ and $70 \%$ homology, respectively, between the AMBR isolate sequences (Table II).

\section{DISCUSSION}

Considering the OMPs in the A. marginale studied, OMP1, OMP5 and OMP10 take on greater importance among antigens derived from the membrane of rickettsia due to their greater than $94 \%$ homology with predicted amino acid sequences of the other isolates studied (Table II). As the inoculation of AMCE can protect against isolates of A. marginale (Pipano 1995), these proteins that have over $65 \%$ sequence homology with AMCE proteins are probably the best candidate vaccine antigens among the OMPs studied.

Most of the AMBR isolate OMP amino acid sequences analyzed in the present study exhibited greater than $92 \%$ homology with the American isolates, indicating that the genes in this family of proteins are also conserved in the Brazilian isolate. However, the predicted OMP15 amino acid sequence in the AMFL isolate (available on Genbank) is not complete and has only 105 amino acids (Fig. 1).

OMP7 was the only protein with predicted amino acid sequence homology below $90 \%$ (Fig. 2). According to Noh et al. (2006), this variation is probably associated with nucleotide substitutions in the central region of this gene, which maintain the reading frame but introduce variations in amino acids. The genes that encode OMPs

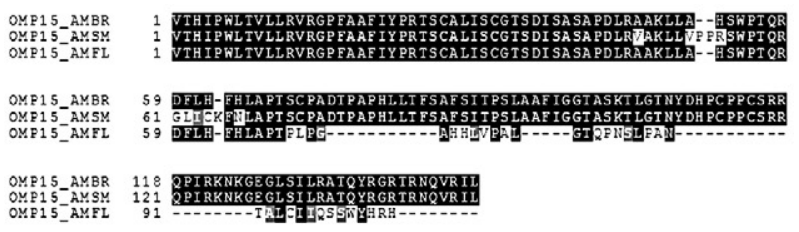

Fig. 1: multiple alignment of the predicted amino acid sequence in OMP15. The sequence is smaller in Anaplasma marginale Florida (AMFL) isolate in comparison to A. marginale Saint Maries (AMSM) and A. marginale Brazilian (AMBR) isolates. 


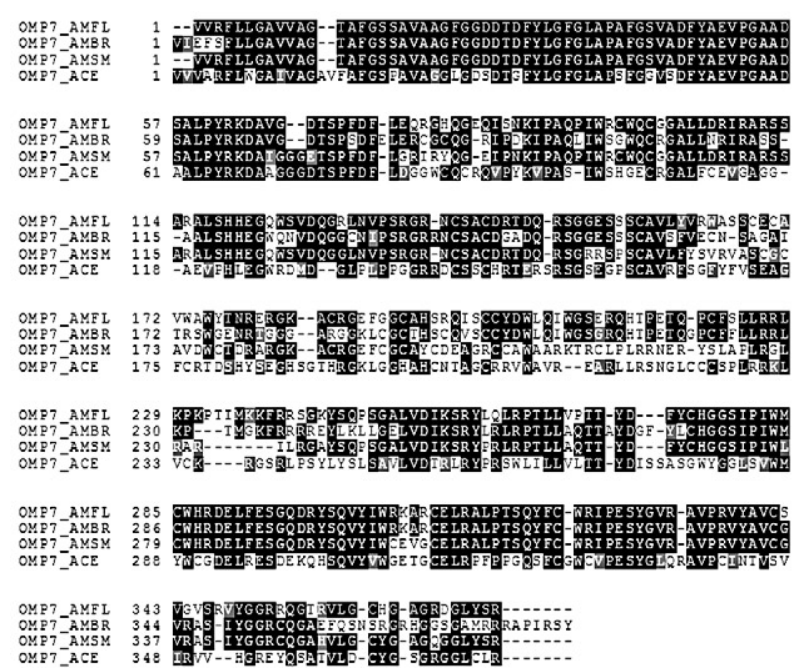

Fig. 2: multiple alignment of the predicted amino acid sequence in OMP7 with low identity between isolates due to the variability of this gene. AMBR: Pernambuco-Zona da Mata isolate of Anaplasma marginale; AMCE: $A$. (centrale) marginale isolate; AMFL: Florida isolate of A. marginale; MSM: Saint Marie isolate of A. marginale.

7-9 share large areas of identity at the 5' and 3' termini, where recombination can occur, while $\mathrm{C}$ and $\mathrm{N}$ terminal areas exhibit relative conservation.

The PepA and EF-Tu were previously classified as cytoplasmic proteins, but an in silico analysis by the TMHMM program suggested them to be proteins anchored to the outer membrane and exposed to the extracellular environment (Lopez et al. 2005). Leucyl aminopeptidase is an enzyme that promotes the breaking of peptide bonds by hydrolysis in the metabolic pathways of amino acids. After alignment, the predicted amino acid sequence of the PepA protein in AMBR isolate exhibited $97 \%$ homology with the sequences of the same protein in AMSM isolate and AMFL isolate and 65\% homology with the gene in AMCE (Table II). The percentage of homology found for this protein sequence is relatively high considering its size (521 amino acids) and the fact that the protein sequence in the sensu stricto American isolate differs from the AMBR isolate sequence by only four amino acids. As PepA, after analysis, was suggested to be a membrane-associated protein and its protein provides a conserved predicted amino acid sequence, more studies should be devoted to the evaluation of its immunogenicity and potential as a vaccine antigen.

EF-Tu is an enzyme belonging to the family of hydrolases involved in protein synthesis, promoting chain elongation during polypeptide synthesis in the ribosome. Ramos et al. (2007) assessed the transcription pattern of several membrane proteins' genes in A. marginale, including EF-Tu, which, after analysis, was suggested to be a membrane-associated protein (Lopez et al. 2005). Araújo et al. (2008) and Lopez et al. (2008) expressed EF-Tu in E. coli and the recombinant protein was able to induce a proliferative response in $\mathrm{T}$ lymphocytes and titers of IgG2 greater than those of IgG1, thereby demonstrating the desired capacity for immunostimulation.
The predicted amino acid sequence of EF-Tu in AMBR isolate exhibited $100 \%$ homology with the sequence in the American isolates and 97\% homology with the sequence in $A$. (centrale) marginale. In comparison to the genes of the membrane proteins investigated in the present study, EF-Tu takes on significance as a possible candidate vaccine antigen, as it exhibits the highest percent homology among the predicted amino acid sequences in the isolates analyzed and is considered a highly conserved gene. This finding corroborates a study carried out by Araújo et al. (2008), who report the conservation of this gene. Moreover, it is capable of stimulating the proliferative response in $\mathrm{T}$ lymphocytes, as reported by Lopez et al. (2008).

The type IV secretion system (TFSS) transports macromolecules through the membrane in an ATP-dependent manner and is related to the conjugation system in Gram-negative bacteria (Niu et al. 2006). TFSS is one of the few groups of syntenic genes among all sequenced Rickettsiales, suggesting that the coordination of the expression of these genes is critical (Hotopp et al. 2006). It is possible that TFSS expression is regulated and associated with survival in intracellular bacteria (Niu et al. 2006). Due to its location on the cell surface, its highly conserved nature and intracellular survival requirements, TFSS proteins in Gram-negative bacteria are consistent targets of immunological investigations (Lopez et al. 2007). In the present study, the predicted amino acid sequences of two TFSS proteins, VirB3 and VirB9-1 (Sutten et al. 2010) were analyzed. The function of VirB3 is not well defined and VirB9-1 is responsible for the transfer of protein-DNA complexes and macromolecules between cells (Lopez et al. 2007).

After alignment with sequences from the previously mentioned isolates, the predicted amino acid sequences of VirB3 and VirB9-1 in AMBR isolate exhibited nearly $100 \%$ homology with the American sensu stricto isolates (Table II) and approximately 96\% homology with AMCE (Table II), demonstrating a high degree of conservation. In studies with other TFSS group members (VirB9-2 and VirB10), Araújo et al. (2008) and Vidotto et al. (2008) suggested conservation among different isolates of $A$. marginale and demonstrated that VirB9-2 and VirB10 proteins are recognized by antibodies from naturally and experimentally infected cattle. The VirB3 protein in AMBR isolate has the same conservation profile as other components of the TFSS group analyzed by Araújo et al. (2008); thus, it is expected to exhibit the same antigen profile, as the conservation of B cell epitopes between and within isolates is likely important for controlling infection. Lopez et al. (2007) also found that VirB9-2, VirB10 and VirB9-1 are conserved among isolates. Furthermore, these proteins are recognized by effector cells of the immune system in cattle inoculated with the outer membrane of $A$. marginale.

Superoxide dismutases (SOD) are metalloenzymes that catalyze the dismutation reaction $\mathrm{O}_{2} \rightarrow \mathrm{H}_{2} \mathrm{O}_{2} \rightarrow \mathrm{O}_{2}$. There are other types of SODs that are distinguished by the metal present in the active site (for example: MnSOD, ZnSOD). According to Ohashi et al. (2002), the $S O D b$ gene in Anaplasma and Ehrlichia spp probably 
encodes a FeSOD. Iron SODs and manganese SODs are known to defend bacterial cells from reactive oxygen generated from the bacterial metabolism and to protect DNA from oxidation damage.

The alignment of the predicted amino acid sequence of SOD of AMBR isolate with the others analyzed in this paper exhibited nearly $100 \%$ homology with SODs from the American sensu stricto isolates (Table II) and $89 \%$ homology with AMCE (Table II). Thus, as SOD is also highly conserved among $A$. marginale strains, the immunogenic potential of this protein should also be examined for vaccine development.

Lopez et al. (2005) annotated AM854 in the A. marginale genome as a putative protein without defined function and a BLAST search showed identity with an OMP and peptidoglycan-associated protein in E. canis. Noh et al. (2008) reported that AM854, along with other proteins, was identified on the surface of $A$. marginale from erythrocytes and tick cells. The predicted amino acid sequence for the am854 gene in AMBR isolate exhibited $100 \%$ homology with the sequences in the American isolates (Table II). According to Lopez et al. (2005), AM854, along with other proteins, was recognized by $\operatorname{IgG}$ in at least one animal, thereby proving to be antigenic. Although the gene that encodes the AM854 protein is not complete, compared to the American isolates, the AMCE genome has a protein annotated as a putative OMP. This protein has 211 amino acids and has $79 \%$ identity (167/211) to the sequence of the American isolates (236 amino acids) when compared using BLAST, showing considerable conservation. This fact must be taken into account, since immunization with this subspecies of Anaplasma is capable of generating a protective immune response against $A$. marginale in cattle (Pipano 1995).

In conclusion, among the predicted amino acid sequences of the proteins evaluated, OMP1, OMP5, EF$\mathrm{Tu}$, VirB3, SODb and VirB9-1 had the highest degrees of homology to the isolates used for comparison purposes (including AMCE) and demonstrated a high degree of conservation. This suggests that these proteins are important to the development of immunogens capable of promoting cross-protection between isolates. Further studies should be carried out to gain a better understanding of the real importance of the EF-Tu, VirB3, SODb and VirB9-1.

\section{REFERENCES}

Araújo FR, Costa CM, Ramos CAN, Farias TA, Souza IIF, Melo ESP, Elisei C, Rosinha GMS, Soares CO, Fragoso SP, Fonseca AH 2008. IgG and IgG2 antibodies from cattle naturally infected with Anaplasma marginale recognize the recombinant vaccine candidate antigens VirB9, VirB10 and elongation factor-Tu. Mem Inst Oswaldo Cruz 103: 186-190.

Barbet AF, Lundgren A, Yi J, Rurangirwa FR, Palmer GH 2000. Antigenic variation of Anaplasma marginale by expression of MSP2 mosaics. Infect Immun 68: 6133-6138.

Brayton KA, Kappmeyer LS, Herndon DR, Dark MJ, Tibbals DL, Palmer GH, McGuire TC, Knowles DP Jr 2005. Complete genome sequencing of Anaplasma marginale reveals that the sur- face is skewed to two superfamilies of outer membrane proteins. Proc Natl Acad Sci USA 102: 844-849.

Brayton KA, Knowles DP, McGuire TC, Palmer GH 2001. Efficient use of a small genome to generate antigenic diversity in tick-borne ehrlichial pathogens. Proc Natl Acad Sci USA 98: 4130-4135.

Brayton KA, Palmer GH, Brown WC 2006. Genomic and proteomic approaches to vaccine candidate identification for Anaplasma marginale. Expert Rev Vaccines 5: 95-101.

Brayton KA, Palmer GH, Lundgren A, Yi J, Barbet AF 2002. Antigenic variation of Anaplasma marginale MSP2 occurs by combinatorial gene conversion. Mol Microbiol 43: 1151-1159.

Brown WC, Shkap V, Zhu D, McGuire TC, Tuo W, McElwain TF, Palmer GH 1998. CD4( $\left(^{+}\right)$T-lymphocyte and immunoglobulin G2 responses in calves immunized with Anaplasma marginale outer membranes and protected against homologous challenge. Infect Immun 66: 5406-5413.

Collins NE, Liebenberg J, de Villiers EP, Brayton KA, Louw E, Pretorius A, Faber FE, van Heerden H, Josemans A, van Kleef M, Steyn HC, van Strijp MF, Zweygarth E, Jongejan F, Maillard JC, Berthier D, Botha M, Joubert F, Corton CH, Thomson NR, Allsopp MT, Allsopp BA 2005. The genome of the heartwater agent Ehrlichia ruminantium contains multiple tandem repeats of actively variable copy number. Proc Natl Acad Sci USA 102: 838-843.

Herndon DR, Palmer GH, Shkap V, Knowles DP Jr, Brayton KA 2010. Complete genome sequence of Anaplasma marginale subsp. centrale. J Bacteriol 192: 379-380.

Hotopp JC, Lin M, Madupu R, Crabtree J, Angiuoli SV, Eisen JA, Seshadri R, Ren Q, Wu M, Utterback TR, Smith S, Lewis M, Khouri H, Zhang C, Niu H, Lin Q, Ohashi N, Zhi N, Nelson W, Brinkac LM, Dodson RJ, Rosovitz MJ, Sundaram J, Daugherty SC, Davidsen T, Durkin AS, Gwinn M, Haft DH, Selengut JD, Sullivan SA, Zafar N, Zhou L, Benahmed F, Forberger H, Halpin R, Mulligan S, Robinson J, White O, Rikihisa Y, Tettelin H 2006. Comparative genomics of emerging human ehrlichiosis agents. PLoS Genet 2: e21.

Lewin B 2000. The operon. In B Lewin (ed.), Genes VII, Oxford University Press, Oxford, p. 275-277.

Löhr CV, Brayton KA, Shkap V, Molad T, Barbet AF, Brown WC, Palmer GH 2002. Expression of Anaplasma marginale major surface protein 2 operon-associated proteins during mammalian and arthropod infection. Infect Immun 70: 6005-6012.

Lopez JE, Beare PA, Heinzen RA, Norimine J, Lahmers KK, Palmer GH, Brown WC 2008. High-throughput identification of T-lymphocyte antigens from Anaplasma marginale expressed using in vitro transcription and translation. J Immunol Methods 332: $129-141$

Lopez JE, Palmer GH, Brayton KA, Dark MJ, Leach SE, Brown WC 2007. Immunogenicity of Anaplasma marginale type IV secretion system proteins in a protective outer membrane vaccine. Infect Immun 75: 2333-2342.

Lopez JE, Siems WF, Palmer GH, Brayton KA, McGuire TC, Norimine J, Brown WC 2005. Identification of novel antigenic proteins in a complex Anaplasma marginale outer membrane immunogen by mass spectrometry and genomic mapping. Infect Immun 73: 8109-8118.

Mavromatis K, Doyle CK, Lykidis A, Ivanova N, Francino MP, Chain P, Shin M, Malfatti S, Larimer F, Copeland A, Detter JC, Land M, Richardson PM, Yu XJ, Walker DH, McBride JW, Kyrpides NC 2006. The genome of the obligately intracellular bacterium Ehrlichia canis reveals themes of complex membrane structure and immune evasion strategies. J Bacteriol 188: 4015-4023. 
Niu H, Rikihisa Y, Yamaguchi M, Ohashi N 2006. Differential expression of VirB9 and VirB6 during the life cycle of Anaplasma phagocytophilum in human leucocytes is associated with differential binding and avoidance of lysosome pathway. Cell Microbiol 8: 523-534.

Noh SM, Brayton KA, Brown WC, Norimine J, Munske GR, Davitt CM, Palmer GH 2008. Composition of the surface proteome of Anaplasma marginale and its role in protective immunity induced by outer membrane immunization. Infect Immun 76 : 2219-2226.

Noh SM, Brayton KA, Knowles DP, Agnes JT, Dark MJ, Brown WC, Baszler TV, Palmer GH 2006. Differential expression and sequence conservation of the Anaplasma marginale MSP2 gene superfamily outer membrane proteins. Infect Immun 74: 3471-3479.

Ohashi N, Zhi N, Lin Q, Rikihisa Y 2002. Characterization and transcriptional analysis of gene clusters for a type IV secretion machinery in human granulocytic and monocytic ehrlichiosis agents. Infect Immun 70: 2128-2138.

Palmer GH, Bankhead T, Lukehart SA 2009. 'Nothing is permanent but change' - antigenic variation in persistent bacterial pathogens. Cell Microbiol 11: 1697-1705.
Palmer GH, Brown WC, Rurangirwa FR 2000. Antigenic variation in the persistence and transmission of the ehrlichia Anaplasma marginale. Microbes Infect 2: 167-176.

Pipano E 1995. Live vaccines against hemoparasitic diseases in livestock. Vet Parasitol 57: 213-231.

Ramos CA, Araújo FR, Osório AL, Madruga CR, Rosinha GM, Soares CO, Elisei C 2007. Transcription of genes of membrane proteins of Brazilians isolates of Anaplasma marginale. Rev Bras Parasitol Vet 16: 152-155.

Sutten EL, Norimine J, Beare PA, Heinzen RA, Lopez JE, Morse K, Brayton KA, Gillespie JJ, Brown WC 2010. Anaplasma marginale type IV secretion system proteins VirB2, VirB7, VirB11, and VirD4 are immunogenic components of a protective bacterial membrane vaccine. Infect Immun 78: 1314-1325.

Tamura K, Dudley J, Nei M, Kumar S 2007. MEGA4: Molecular Evolutionary Genetics Analysis (MEGA) software version 4.0. Mol Biol Evol 24: 1596-1599.

Vidotto MC, Venâncio EJ, Vidotto O 2008. Cloning, sequencing and antigenic characterization of rVirB9 of Anaplasma marginale isolated from Paraná state, Brazil. Genet Mol Res 7: 460-466. 